\title{
On the 80th Birthday of Jan van Bemmel
}

\author{
Marion J. Ball', Dieter Bergemann², Arie Hasman³, Reinhold Haux, Alexa T. McCray5, \\ Johan van der Lei ${ }^{6}$ \\ 1 Healthcare Informatics, Center for Computational Health, IBM Research, USA \\ 2 Schliersee, Germany \\ 3 Dept. of Medical Informatics, Academic Medical Center, UvA, Amsterdam, the Netherlands \\ 4 Peter L. Reichertz Institute for Medical Informatics, TU Braunschweig and Hannover Medical \\ School, Germany \\ 5 Harvard Medical School, Boston, Massachusetts, USA \\ 6 Dept. of Medical informatics, Erasmus University, Rotterdam, the Netherlands
}

\section{Introduction}

On November 17, 2018 Jan van Bemmel had his 80th birthday. Because of Jan van Bemmel's role in our medical informatics discipline the idea arose to invite a number of close colleagues to write a contribution in which, when possible, they would review one or more papers of Jan van Bemmel using the knowledge about medical informatics we have today. A number of topics were suggested: about medical informatics as a scientific discipline, about his contributions with respect to ECG analysis and evaluation, about information systems, and about his role in medical informatics education. The contributions of Reinhold Haux (section 2), Johan van der Lei (section 3), Marion Ball (section 4) and Arie Hasman (section 5) review some of Jan's publications on the before mentioned topics. In addition, contributions about his international collaboration and communication and his work as an editor of the IMIA (International Medical Informatics Association) Yearbook of Medical Informatics and of Methods of Information in Medicine were included. These latter contributions were written by Alexa McCray (section 6) and Dieter Bergemann (section 7). We end this paper with congratulations to Jan van Bemmel.

\section{Jan van Bemmel on Medical Informatics as a Scientific Discipline (Reinhold Haux)}

Jan van Bemmel was among the first, who explicitly published on medical informatics as a scientific discipline. Core publications in this context are:

$\mathrm{S}_{1}$ "A comprehensive model for medical information processing" [1], published in 1983 ,

$\mathrm{S}_{2}$ "The structure of medical informatics" [2], published in 1984,

$\mathrm{R}_{1}$ "Medical informatics, art or science?"[3], published in 1996,

$\mathrm{C}_{1}$ "The young person's guide to biomedical informatics" [4], published in 2006,

$\mathrm{C}_{2}$ "Reflections on curiosity" [5], published in 2008 ,

$\mathrm{C}_{3}$ "People and ideas in medical informatics - a half century review" [6], published in 2011.

S stands for searching, as these publications reflect his (re-)search on medical informatics as a scientific discipline and on how this discipline can be structured. In this $S$-Period, Jan was in the forties and professor at the Free University of Amsterdam. R stands for reflecting, as the art-or-science-paper summarizes his view of medical informatics as a scientific discipline - with its potentials, its achievements, and its challenges. In this R-Period, Jan was in his fifties and professor at the Erasmus University of Rotterdam. C stands for concluding on medical informatics as a field, on the requirements for its researchers, as well as on its role in the family of sciences and beyond. In this $C$-Period, Jan was in his late sixties/early seventies and professor emeritus.

Although most of his publications were with co-authors, Jan was in these six publications the only author. This was probably for two reasons. The one is that these publications contained his personal views. The other is that there are probably only few persons, working in this depth and in this quality on the demanding topic of medical informatics ${ }^{1}$ as a scientific discipline. Two publications have to be added in this context. Jan also stated his view in a panel discussion named "Can health/medical informatics be regarded as a separate discipline?", published in 1994 ([7], p. 323-324.) and in an editorial of a workshop on "Challenges for medical informatics as academic discipline", which he co-organized, published in 2002 [8]. Both publications can be assigned to Jan van Bemmel's R-Period.

or, as many colleagues would say today, on biomedical and health informatics, or, briefly, on informatics. 
Let me very briefly highlight some aspects that Jan van Bemmel mentioned on medical informatics as a scientific discipline in these three periods. And let me invite and encourage all readers to take a look at these papers themselves. They are wonderful, rich sources on learning and reflecting about medical informatics as scientific discipline.

In Jan van Bemmel's S-period, he discussed on properties of sciences with statements like „Science is concerned with generalizations and abstractions of reality in order to comprehend the structure behind it and to control aspects of it." ([1], p. 124), while then introducing his model ,for computer applications in medicine" ([2], p. 176), see figure 1.

In the art-or-science-paper of his R-Period, Jan van Bemmel comprehensively analyses informatics as a discipline by means of examples and once again structured according to the levels of his working model. The following quote may point out Jan's differentiated view on medical informatics as a scientific discipline: "It is sometimes asserted that medical science is no different than any other science. I would strongly disagree ...; medical science ... draws upon a number of lower-level sciences, while physics, for example does not. This obvious state of affairs ... has profound consequences. Because medicine derives its experimental content from a set of sciences ..., the processing of the observational data of medicine faces a number of problems. This is one of the reasons why there is a "medical" information science, and why there is not a 'physics' information science." ([3], p. 162). In [7], pp. 323-4, he wrote "Is medical informatics a separate discipline and will medical informatics survive in the years to come? The answer to the first question is: yes; look at the field right now. The answer to the second question is: perhaps; it is entirely dependent on future needs ... and the methodology to be offered by medical informatics ... . I have no doubt that for many years to come the need for medical informatics will be high and the methods to be offered sound and scientific. Many challenging problems still lie ahead to be solved by medical informatics."

In Jan van Bemmel's C-Period he is more than before emphasizing the need for interdisciplinarity, which is particularly an

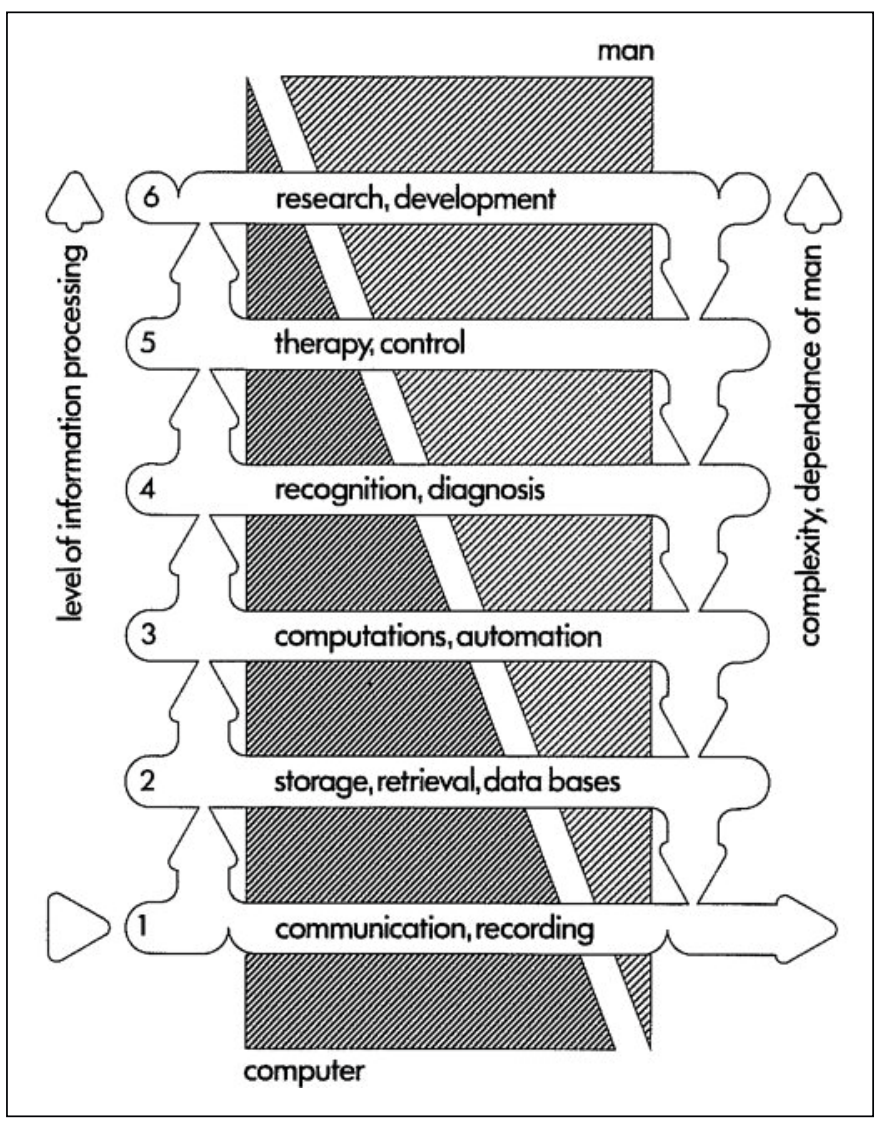

Fig. 1 Jan van Bemmel's „working model or schematic representation for the ordering of computer applications in medicine". Taken from [1], p. 125. important and necessary property of medical informatics and of researchers in this field. Based on his profound knowledge from his previous periods and due to experience gained during his long and outstanding professional career (and not only there), his view comprises more and more sciences in general. In [6], p. 175, Jan wrote: "Our field has been and continues to be in a state of rapid development. After medical informatics came into being, several other informatics-related branches also sprouted from the tree of medicine, such as genomics and proteomics. At the same time other branches, such as physiology or anatomy, were intertwined with yet other ones. Perhaps, sooner or later, this will also occur to medical informatics." In [5], p. 183, he starts with statements like "Curiosity is characteristic of children as well as researchers. ... This was - and still is - the main motivation behind the research I conducted all my life. Therefore, this article is on curiosity, but it spreads out further than just biomedi- cal informatics." Medical informatics is regarded as a discipline within the great and ever changing family of sciences, which itself is just part of something else. In Jan van Bemmel's words and with curiosity: "We try to unravel in our research the structure behind what we observe in living and non-living nature." ([5], p. 187).

\section{Jan van Bemmel on ECG Analysis and Evaluation (Johan van der Lei)}

Jan van Bemmel had throughout his career a keen interest in the computer interpretation of electrocardiograms. He was one of the investigators who collectively faced the challenge: how to assess the diagnostic performance of computer programs for the interpretation of electrocardiograms. The paper on this topic appeared in the New England Journal of 
Medicine (NEJM) in 1991 [9]. And the paper also set the standard for evaluating programs that interpret ECGs for years to come.

Reading the paper again more than 25 years later, one is struck by the keen insight of the authors; insight that is still relevant today where Big Data Analytics and Artificial Intelligence are buzz words.

In their paper in 1991, the authors emphasized the need to systematically assess programs that interpreted ECGs. They lament that evaluations are often reported, but not in a consistent fashion and that they are typically limited to a single site. They argue that the starting point of an evaluation is the establishment of a library of validated ECG recordings. They acknowledge that collecting validated ECGs is an arduous task. But their keen insight that these validated ECGs are the corner stone of evaluation was correct. At present, investigators can only underscore that well documented test cases have proven essential in a broad range of fields when assessing the performance of computer programs.

In their study, the authors also carefully design the comparison of computer programs to the performance of human experts. The library of validated ECG recordings provided the 'Gold Standard'. The performance of both humans and computers was determined using similar methodology thus encouraging the reader to continuously compare them. As a result, many conclusions of the study are cast in terms that contrast the two. This is reflected in the conclusion of the abstract of their study: "Our study shows that some but not all computer programs for the interpretation of ECGs perform almost as well as cardiologists in identifying seven major cardiac disorders". Nowadays researchers assessing the performance of diagnostic systems still face the same challenge: how to contrast the performance of a machine with that of human experts. This early study shows the power of a direct comparison of humans with computer programs in framing the performance of both.

A number of different ECG interpretation programs were available in the late eighties of the last century. Striking in their design of the study was the use of the "Combined Opinion" in which the results of the different computer programs are combined resulting in a single diagnosis. They introduce an "ensemble system" - albeit that the combination algorithm is a simple majority vote. Again, they treat the human experts the same way: combining the opinion of the different experts into a single diagnosis in the same way as they combined the results of the computer programs. In subsequent years, the use of ensemble systems that combine different systems into a single diagnosis became increasingly common.

The authors argue that the ECG-reading program can assist clinicians in achieving more uniform and consistent interpretations. They take great care in articulating that computers should only play a limited role. When reading the original paper, one is struck by the emphasis the authors place on the fact that expert cardiologists should always validate the reports of ECG interpretation systems. In an accompanying editorial in the NEJM entitled "Computerised Electrocardiography: an adjunct to the physician" [10], Laks and Selvester continue this line of reasoning and argue that "every computerized ECG must be read and modified as needed by a competently trained physician". But what if a diagnostic system begins to outperform the human? Maybe in the coming years we will need to reflect again on the relationship between humans and computers when diagnosing a patient. And maybe the authors were in 1991 too careful in paying tribute to the role of human experts.

\section{Jan van Bemmel on Information Systems (Marion Ball)}

Looking back at his incredible contributions to the field of medical informatics, I want to highlight, particularly, the work that he did on healthcare workstations and versatility of computerized patient records. I refer to the papers he wrote, as early as 1994 and 1999, when he presented us with the then state-of-the-art thinking regarding the use of computerized patient records at the point of care. The architectures that he described and named HERMES and ORCA laid out the issues we are still grappling with today!

In many ways the systems and architectures that he and his colleagues developed in the 90 s were so far ahead of what are still key issues we are trying to solve in the United
States today. He predicted the importance of interoperability among a variety of healthcare applications/specialties that needed to be integrated into one workstation architecture for good patient care, as well as addressing the all-important user-friendly interface, for both the provider and consumer.

I quote from his 1994 paper HERMES: a healthcare workstation integration architecture [11]. "By means of this architecture, data from different sources dispersed in a network can be combined and directly used in existing applications or applications that have been developed specifically for integration. This feature of combining data from different sources into one workstation is viewed as an enabling technology on which computer-based patient records can be built."

To this day, slowly but surely, progress is being made. However, his original design and implementation for healthcare was already his vision over 25 years ago!

In his paper written in 1999 [12] entitled ORCA: the Versatile CPR, he shows us a generic computer-based patient record (CPR) as he states "designed, for integration with existing systems, presentation of multi-media patient data, and the collection of structured data, directly by clinicians." He had already addressed visualization and multi-media to provide the best possible information for the clinician to have at his or her fingertips at the point of care.

These two references are just a bird's eye view into the tremendous vision he has had into our fields of medical informatics, cardiology, radiology, and many other specialties that have so benefited from his ideas. He brought enabling technologies to a variety of specialties, integrating them into a successful working computerized patient record environment.

\section{Jan van Bemmel on Medical Informatics Education (Arie Hasman)}

I was privileged to work with Jan van Bemmel from the start of the newly created department of Medical Informatics at the Free University in Amsterdam. Therefore, I both observed 
and took part in the development of Medical Informatics education for medical students (and later also informatics students) under the leadership of Jan van Bemmel.

$\mathrm{He}$ started giving lectures to medical students in the second year of their study and the contents of these lectures were published in 'Introduction to Medical Informatics' [13], published in 1981. In addition, elective courses could be followed in the third and fourth year. In the fifth year, elective block courses were organized four times a year [14]. The block course was a mixture of lectures and practicals and its duration was five days. The topics were dealt with in a certain order, which constituted the foundation of the so-called model for medical information processing to be discussed shortly. Finally, the Handbook of Medical Informatics [15] appeared with contributions of a number of authors, edited by Jan van Bemmel and Mark Musen.

Apart from these educational activities Jan van Bemmel was also the chairman of the Subcommittee Medical Informatics of the Committee for Medicine of the Royal Netherlands Academy of Arts and Sciences. In 1987, recommendations for education and training in medical informatics were formulated by this Subcommittee. The report 'Medical Informatics, Renewal in Medicine' of this Subcommittee [16] proposed the content for the introductory education in medical informatics. Also, it was stressed that medical students should get practical experience so that they would understand the possibilities and limitations of information systems.

Jan van Bemmel realized that it was important to look for order in the field of medical information processing to see whether a model can be conceived that will help to perceive the structure behind the host of solutions to medical problems with the help of information processing. The diversity of computer applications at that time was such that neither medical students nor medical doctors would be able to see the trees through the wood. The model was published in 1983 [1]. This model influenced the way lectures were structured in many medical informatics programs.

The model consisted of six levels of complexity (see Fig. 1). He showed that there existed many more applications at the lower levels of the model, due to the fact that at these levels the complexity is relatively low and therefore the chance of being able to create a successful application relatively large. Applications on the higher levels are more difficult to develop because usually the processes that these applications have to support are not so well understood that an all-embracing solution can be formalized.

Jan van Bemmel did not provide a definition of complexity. He mentioned that complexity and degree of user dependence were somewhat related in the sense that a higher complexity meant a higher degree of user dependence. The model was widely accepted and as far as I know not criticized. I also never had any problems with the model. The sequence of the tasks of the different levels appeared quite logical to me: tasks at higher levels could need tasks at lower levels but not vice versa. But I am not sure whether, for example, communication software that, when forwarding packets through the network, has to take into account the traffic on the network and the possible existence of faulty connections is in principle less complex than database systems. At the third level of computations and automation perhaps more problems need mathematics to be solved. But does that make the task more complex? It depends on the background of the software analyst whether (s)he experiences such a problem as more or less complex. What makes the upper three levels more user dependent, as also stated by Jan van Bemmel, is the fact that in a number of situations an expert cannot verbalize his or her tacit knowledge so that no formalization of parts of the knowledge is possible, even though the expert is able to solve the problem. In these cases, programs depend on the user to solve the missing parts. Another issue is that at the levels of recognition, diagnosis and treatment ethical issues play a role: only human beings can be responsible for the decisions made. Therefore, user dependence becomes large at these levels. At the sixth level of research the user is in control. For carrying out research, creativity and intuition are important traits. Also, here there may be ethical problems involved when selecting research topics.

I am not so sure anymore whether information systems cannot carry out those parts of a task for which the knowledge needed cannot be formalized. Big data analytics has shown that image recognition with the help of neural nets (deep learning) can be as good as recognition by human beings and these nets determine themselves the features that discriminate different objects. So tacit knowledge does not always make a task more complex. But now solutions provided by information systems based on neural networks are not transparent any more to the users. How can a user be responsible if he does not understand why a certain diagnosis is provided by the system? It raises an ethical problem. The user has to obtain further patient information in order to validate the diagnosis of the system. So, in my opinion the first three levels of the model are in the correct logical order but whether that order is determined by complexity I do not know. The highest three levels on the contrary will be dependent on users: the user has to find additional information to corroborate the system's conclusions.

Jan van Bemmel's model in my opinion will survive. As said the proposed sequence is logical. Perhaps the explanation of what causes the different levels has to be changed a bit, but the model still is a powerful tool for educating students.

\section{Jan van Bemmel and International Collaboration and Communication (Alexa McCray)}

Jan van Bemmel has been involved internationally throughout his career. As a scholar, he contributed to the world-wide scientific literature, as an educator he collaborated with others in training individuals across national boundaries, as a leader in international societies he worked to enrich the experiences of researchers, no matter whether they were from high-resource or low-resource settings, and as an editor he promoted global access to scientific information. This latter was most evident in his work on the IMIA Yearbook.

The first edition of the IMIA Yearbook was launched in 1992, and its first editors were Jan van Bemmel and Alexa McCray, 
who collaborated on the publication of the Yearbook throughout the 1990's. The early editions of the Yearbook were published well before the Internet became ubiquitous and were published in book form ${ }^{2}$. In most cases, the Yearbook was purchased in bulk by IMIA's national member societies and was seen as a valuable membership benefit, not only because of its scientific content, but also because it served as an important resource for information about IMIA itself. Information that otherwise would have been difficult to access about the activities of IMIA's national member societies as well as its regional societies and working groups was submitted by those groups and was readily available in the front matter of the Yearbook. The number of Yearbooks disseminated world-wide each year was approximately 10,000 copies [17-25].

From the beginning, the editors focused on the international scope of the Yearbook, with a special emphasis on its potential impact as a research and educational resource for anyone with an interest in informatics throughout the world. Indeed, the first sentence of the editorial in the inaugural edition of the Yearbook is: "The 1992 IMIA Yearbook of Medical Informatics reflects the worldwide research and development in medicine and health care where computers play an essential role." [17].

The annual Yearbook was intended as a compilation of high-quality, peer-reviewed, methodologically sound informatics articles that had appeared in the previous year. The selection process was rigorous. Referees from the international medical informatics community were asked to assess the quality of each article along a variety of dimensions, including, importantly, impact on the field. Each volume reflected the broad diversity and international scope of research in health and biomedical informatics. Articles were selected from the informatics literature, and also from medical journals, technical or engineering journals, and basic science journals. Each edition included approximately fifty reprinted papers and represented the work of individuals from around the world.

\footnotetext{
2 Since 2014, the Yearbook has been published exclusively online.
}

Beginning with the second edition, the editors also invited several experts to write articles that reviewed the state-of-the-art in specific areas of the field [18]. This was expanded by the third edition, and a new component was introduced that featured descriptions of informatics education and training programs in different parts of the world [19]. Each of the subsequent editions included this feature [19-25]. Beginning with the fourth edition, the editors invited original papers that were specifically targeted to the theme of that year's Yearbook and that tradition was followed in the subsequent editions [20-25]. Each year, the reprinted papers were grouped into sections, which reflected the broad range of topics that comprise the field. Beginning with the fourth edition, guest editors were invited to write synopses of these different sections. Over time, including the contributions of referees, guest editors, review writers, editors and managing editors, the production of each edition of the Yearbook thus involved dozens of individuals from the international health and biomedical informatics community.

The Yearbook is still published annually to this day. In 2016, the Yearbook celebrated its twenty-fifth anniversary, and the original editors were asked to comment on the promise of the field, with an eye to its past and the exciting challenges for the future [26].

\section{A Publisher's Dream of How Medical Informatics Journals Should be Managed (Dieter Bergemann)}

From 1988 until 2001 Jan van Bemmel was Editor-in-Chief of our journal Methods of Information in Medicine [27]. Speaking of "our journal" reflects my memories, as I have been owner and publisher of Schattauer Verlag for more than 30 years. The chance to work with Jan on this journal was a lucky coincidence for me, both professionally and personally. Based on Jan's excellent international reputation and with his connections worldwide, Methods of Information in Medicine could develop to one of the leading international journals in informatics. Even more, besides the pleasure of jointly working with him on this journal, we became friends.

Jan's nomination to become editor of Methods came from the journal's founding editor, Professor Gustav Wagner, Heidelberg, as well as from Professor Peter L. Reichertz, Hannover. Thanks to both of them a first meeting with Jan van Bemmel and me took place in 1986 in Amsterdam. Additional meetings followed later in Rotterdam and in Stuttgart. There we got introduced to our quite different working environments: on the one hand the impressive view from the 21 st floor of the Erasmus University Medical Center Building, where Jan van Bemmel's institute was located, and on the other hand, the conservative mansion of the publishing house in Stuttgart. We learned to know the staff of the medical informatics institute and of the publishing house. And, also, our families met.

During his time as editor, Jan was a busy world traveller, also having many obligations at his University. Often his editorial work had to be done during his travels and even on flights. In spite of his very tight schedule, deadlines for publishing journal issues were always kept and his editorial work was done in high quality. His editorials at the beginning as well as at the end of his editorship may at least to some extent give a view on the visions, he had as editor of this journal [28], [29].

At the beginning of the 1990s, Jan was also strongly involved in another large publication project: the IMIA Yearbook of Medical Informatics, with its first volume appearing in 1992, edited by him and by Professor Alexa McCray [17]. Also for this publication, Schattauer Verlag was chosen as partner and publishing house. As with Methods of Information in Medicine, the work of the editors, and so with Jan, was highly professional. Besides, our collaboration always took place in a very constructive and friendly manner.

Because of his tight schedule we often had to meet during weekends. There we added 'private components' like attending wonderful classical concerts or like eating 'nieuwe haring'. Our friendship remains until today, in spite of our geographic distance. At least one time per year we meet 
in Jan's favourite winter holiday location, at Ramsau, Dachsteingebirge, in Austria. I already look forward to meeting each other the next time.

\section{On Jan's Birthday}

All of us in the field of biomedical and health informatics have benefited so greatly from Jan's efforts, giving so many years to advancing the use of technology in healthcare. Today on his 80th birthday, we want to give homage to his many accomplishments and thank him again for not only his devotion to the field but also for the many people he has mentored and helped along the way. We also appreciate the caring he has shown not only to his family, but to many of us who are privileged to know him. With our deepest respect, we wish you, Jan, a Very Happy Birthday!

\section{References}

1. van Bemmel JH. A comprehensive model for medical information processing. Methods Inf Med 1983;22:124-30.

2. van Bemmel JH. The structure of medical informatics. Med Inform 1984:9:175-80.

3. van Bemmel JH. Medical informatics, art or science? Methods Inf Med 1996;35:157-72; discussion 173-201.

4. van Bemmel JH. The young person's guide to biomedical informatics. Methods Inf Med 2006;45:671-80
5. van Bemmel JH. Reflections on curiosity. Yearb Med Inform 2008:183-8.

6. van Bemmel JH. People and ideas in medical informatics - a half century review. Yearb Med Inform 2011:175-82.

7. Protti DJ, van Bemmel JH, Gunzenhüser R, Haux $\mathrm{R}$, Warner H, Douglas JV, et al. Can health/medical informatics be regarded as a separate discipline? Methods Inf Med 1994;33:318-26.

8. Musen MA, van Bemmel JH. Challenges for medical informatics as academic discipline. Methods Inf Med 2002;41:1-3.

9. Willems JL, Abreu-Lima C, Arnaud P, van Bemmel JH, Brohet C, Degani R, et al. The diagnostic performance of computer programs for the interpretation of electrocardiograms. N Engl J Med 1991;325(25):1767-73.

10. Laks MM, Selvester RH. Computerized electrocardiography--an adjunct to the physician. N Engl J Med 1991;325(25):1803-4.

11. van Mulligen EM, Timmers T, Brand J, Cornet R, van den Heuvel F, Kalshoven M, van Bemmel JH. HERMES: a health care workstation integration architecture, Int J Biomed Comput 1994;34(14):267-75.

12. van Ginneken AM, Stam H, van Mulligen EM, de Wilde M, van Mastrigt R, van Bemmel JH. ORCA: the Versatile CPR, Methods Inf Med 1999;38:332-8.

13. van Bemmel JH. Inleiding Medische Informatica (in Dutch). Utrecht: Bohn, Scheltema and Holkema; 1981.

14. van Bemmel JH, Hasman A, Sollet PCGM, Veth AFL. Training in medical informatics. Comput Biomed Res 1983;16:414-32.

15. van Bemmel JH, Musen MA (editors). Handbook of Medical Informatics. New York: Bohn, Stafleu and Van Loghum, Houten and Springer-Verlag; 1997.

16. van Bemmel JH and Festen C (editors). Medical informatics renewal in medicine (in Dutch with English summary). Amsterdam: Committee for Medicine of Royal Netherlands Academy of Arts and Sciences; 1987.

17. van Bemmel JH, McCray AT (editors). Yearbook of Medical Informatics - Advances in an interdisciplinary science. Stuttgart: Schattauer Verlag; 1992.

18. van Bemmel JH, McCray AT (editors). Yearbook of Medical Informatics - Sharing knowledge and information. Stuttgart: Schattauer Verlag; 1993.

19. van Bemmel JH, McCray AT (editors). Yearbook of Medical Informatics-Advanced communications in healthcare. Stuttgart: Schattauer Verlag; 1994.

20. van Bemmel JH, McCray AT (editors). Yearbook of Medical Informatics - The computer based patient record. Stuttgart: Schattauer Verlag; 1995.

21. van Bemmel JH, McCray AT (editors). Yearbook of Medical Informatics - Integration of information for patient care. Stuttgart: Schattauer Verlag; 1996.

22. van Bemmel JH, McCray AT (editors). Yearbook of Medical Informatics - Computing and collaborative care. Stuttgart: Schattauer Verlag; 1997.

23. van Bemmel JH, McCray AT (editors). Yearbook of Medical Informatics - Health informatics and the Internet. Stuttgart: Schattauer Verlag; 1998.

24. van Bemmel JH and McCray AT (editors). Yearbook of Medical Informatics - The promise of medical informatics. Stuttgart: Schattauer Verlag; 1999.

25. van Bemmel JH, McCray AT (editors). Yearbook of Medical Informatics - Patient-centered systems. Stuttgart: Schattauer Verlag; 2000.

26. van Bemmel JH, McCray AT. The renewed promise of medical informatics. $25^{\text {th }}$ anniversary of the Yearbook of Medical Informatics. Yearb Med Inform 2016;Suppl 1: S12-7.

27. McCray AT, Gefeller O, Aronsky D, Leong TY, Sarkar IN, Bergemann D, et al. The birth and evolution of a discipline devoted to information in biomedicine and health care. As reflected in its longest running journal. Methods Inf Med 2011:50:491-507.

28. van Bemmel JH. Medical data, information, and knowledge. Methods Inf Med 1988;27:109-10.

29. van Bemmel JH. Transferring the helm. Methods Inf Med 2001;48:68-9. 